\title{
SCIENTIFIC REPORTS

\section{Bridging population genetics and the metacommunity perspective to unravel the biogeographic processes shaping genetic differentiation of Myriophyllum alterniflorum DC.}

\author{
Jorge García-Girón $\mathbb{D}^{1 *}$, Pedro García $\mathbb{B}^{2}$, Margarita Fernández-Aláez $\mathbb{D}^{1}$, Eloy Bécares $\mathbb{B}^{1}$ \& \\ Camino Fernández-Aláez $\mathbb{D}^{1}$
}

The degree to which dispersal limitation interacts with environmental filtering has intrigued metacommunity ecologists and molecular biogeographers since the beginning of both research disciplines. Since genetic methods are superior to coarse proxies of dispersal, understanding how environmental and geographic factors influence population genetic structure is becoming a fundamental issue for population genetics and also one of the most challenging avenues for metacommunity ecology. In this study of the aquatic macrophyte Myriophyllum alterniflorum DC., we explored the spatial genetic variation of eleven populations from the Iberian Plateau by means of microsatellite loci, and examined if the results obtained through genetic methods match modern perspectives of metacommunity theory. To do this, we applied a combination of robust statistical routines including network analysis, causal modelling and multiple matrix regression with randomization. Our findings revealed that macrophyte populations clustered into genetic groups that mirrored their geographic distributions. Importantly, we found a significant correlation between genetic variation and geographic distance at the regional scale. By using effective (genetic) dispersal estimates, our results are broadly in line with recent findings from metacommunity theory and re-emphasize the need to go beyond the historically predominant paradigm of understanding environmental heterogeneity as the main force driving macrophyte diversity patterns.

The degree to which dispersal limitation interacts with environmental filtering has intrigued metacommunity ecologists and population geneticists since the beginning of both research disciplines ${ }^{1}$. Today, metacommunity ecology has rapidly become a dominant framework through which ecologists understand the natural world ${ }^{2}$. Both, population genetics and metacommunity ecology, posit that it is not only the local environment that dictates patterns of species distributions, but these patterns also depend on processes such as the movement of organisms at the regional scale ${ }^{3,4}$. Each has generated an impressive body of theoretical and empirical research over the past two decades, yet dispersal processes operating in aquatic organisms remain little explored ${ }^{5}$. This deficit is a major hindrance to our understanding of dispersal as a force structuring regional patterns of biodiver$s i^{6}{ }^{6}$, and is also the main reason why ecologists usually need to rely on proxies for dispersal. Recent simulation studies have shown that this typical coarse interpretation of spatial-based processes, which is primarily derived from the use of orthogonal spatial eigenvectors $\left(\mathrm{MEM}^{7}\right)$ in variation partitioning analysis, is to some degree flawed, resulting in greatly inflated estimates of the role of environmental filtering. Consequently, much of modern freshwater ecology is founded on the principle of environmental determinism and its findings are still subject

${ }^{1}$ Group for Limnology and Environmental Biotechnology, Area of Ecology, Universidad de León, Campus de Vegazana, León, Spain. ${ }^{2}$ Department of Molecular Biology, Universidad de León, Campus de Vegazana, León, Spain. *email: jogarg@unileon.es 
to revision. In this vein, the recent macroecological study of Alahuhta et al. ${ }^{9}$ (using partial redundancy analysis and the standard variation partitioning approach) showed that environmental filtering overrode the effects of potential connectivity in explaining local communities across the world. However, such a statistical approach is highly correlative and was recently shown to overlook the role of dispersal-related processes on species distributions at a landscape level ${ }^{8}$.

Recent recognition of the limitations affecting the traditional community-based approach to assess the relationships between dispersal limitation and environmental filtering called for the development of more sophisticated empirical methods ${ }^{10}$. In this context, it is important that ecologists take advantage of modern techniques that have the potential to inform robust mechanistic models ${ }^{11}$. These techniques include molecular tools, which have been historically employed to study gene flow and potential dispersal limitation in biological populations ${ }^{12,13}$. Since gene flow estimations are certainly superior to coarse proxies of dispersal, understanding how environmental and geographic factors influence the genetic structure of biodiversity is becoming one of the most fundamental issues for population genetics ${ }^{14}$ and also one of the most challenging avenues for metacommunity ecology ${ }^{10}$. Consequently, progress in the synergistic potential of population genetics and metacommunity ecology may help in elucidating the degree to which dispersal limitation interferes with the local environment in determining geographic patterns of biological diversity.

Landscape genetic scenarios, including 'isolation by distance' (IBD) and 'isolation by the environment' (IBE), rely on inferring the role of dispersal limitation and environmental variation from observed patterns of genetic structure. The theory of isolation by distance describes the local accumulation of genetic differences when dispersal among populations is limited by geographic factors, and therefore gene flow is inversely proportional to the distance between populations $s^{4,15}$. Thus, genetic differentiation is the result of drift acting within populations more quickly than it is mitigated by gene flow among populations ${ }^{14,15}$.

Conversely, when genetic differentiation positively aligns with environmental dissimilarity among sites, a pattern of isolation by environment emerges ${ }^{4}$. This model suggests that environmental variables can influence the colonisation success of individuals and groups of individuals via environmental filtering, with higher effective gene movements among similar environments ${ }^{4,14}$. Hence, regional variation in the environment may influence species-specific colonisation rates and establishment success when geographic distance allows dispersing immigrants to reach nearby habitat patches ${ }^{14}$. A classic example of this scenario in the freshwater realm comes from plants growing on and near the reaches of lakes and rivers, where local adaptations to different sediment and soil types have occurred ${ }^{4}$. Both patterns of IBD and IBE are usually present simultaneously in nature ${ }^{4}$ and represent one of the most important approaches with which to assess the relative importance of geographic distance and environmental heterogeneity in shaping patterns of dispersal and genetic variation ${ }^{14,16,17}$.

Relatively few empirical studies have examined the contribution of dispersal limitation and environmental filtering on macrophyte genetic divergence ${ }^{16-18}$. The few existing studies ${ }^{16-19}$ seem to reveal simultaneous IBD and IBE patterns in shaping the genetic structure of different aquatic macrophyte species. Importantly, the interaction between spatial and environmental dynamics in structuring macrophyte genetic differentiation is broadly in line with recent findings from metacommunity theor $\mathrm{y}^{20,21}$, and emphasizes the need to go beyond the historically predominant paradigm of understanding environmental specificity as the main force driving macrophyte gene flow patterns $\mathrm{s}^{22,23}$.

Here, we present an analysis of geographic genetic variation using microsatellite markers on a total of 11 populations of Myriophyllum alterniflorum DC. $(2 \mathrm{n}=14)$ from 11 ponds located in the Iberian Plateau. More specifically, our main aims were to: (i) explore geographic patterns of population genetic structure and gene flow in the alternateflower watermilfoil; (ii) assess the influence of geographic distance and environmental dissimilarity on genetic differentiation of M. alterniflorum in Mediterranean pond environments; and (iii) disentangle if results obtained through population genetic methods match modern perspectives of metacommunity theory in these landscapes. Based on evidence from previous genetic studies on aquatic macrophytes ${ }^{16-19}$, we expected both geographic distance and environmental filtering to influence genetic variation of $M$. alterniflorum at the regional scale (H1). We also assumed that habitat fragmentation in Mediterranean landscapes would require that gene flow occurs primarily between neighbouring populations (H2), supporting recent metacommunity empirical research $^{20,21}(\mathbf{H} 3)$ that suggests that spatial structuring accounts for much of the variation in aquatic macrophyte diversity patterns.

Since no academic work has yet examined the actual patterns of gene flow in aquatic macrophytes from a Mediterranean perspective, we hope that the baseline genetic information of our work may provide ground-breaking insights into the role of geographic isolation and environmental filtering on macrophyte metapopulation structuring. Similarly, our findings may have important and widespread implications for integrating population genetics into the full inference space of metacommunity ecology, helping us obtain a deeper understanding of whether or not spatial processes may hinder aquatic macrophytes from tracking environmental variation at the regional scale. It is important to emphasise that our study is limited to a single macrophyte species, and since most metacommunities comprise dozens to hundreds of species, findings should therefore be handled with caution. This is because, although the fundamental units are analogous (taxa in communities, alleles in populations), population genetics and metacommunity ecology use different routines and approaches to disentangle geographic patterns of biological diversity ${ }^{3,4}$. However, it is now becoming feasible to compare community assessments with genetic variation of single or a few species ${ }^{10}$. Whatever the case, we strongly believe that the alternateflower watermilfoil offers an ideal example for us to assess the spatial genetic patterns of aquatic macrophytes because it occurs irrespectively in still or slow-moving water of lakes, ponds and rivers and it is also widely distributed in different biogeographic realms of the Earth ${ }^{19}$. 


\begin{tabular}{|l|l|l|l|l|l|l|l|l|l|l|l|}
\hline Populations & Latitude & Longitude & $\begin{array}{l}\text { Population } \\
\text { size }\end{array}$ & $\begin{array}{l}\text { Number of } \\
\text { genotypes }\end{array}$ & $\mathbf{N}_{\mathbf{a}}$ & $\mathbf{N}_{\mathbf{e}}$ & $\mathbf{H}_{\mathbf{o}}$ & $\mathbf{u H}_{\mathrm{E}}$ & $\mathbf{F}_{\text {IS }}$ & PCA1 & PCA2 \\
\hline AMO & 4682078 & 310393 & 13 & 13 & 4.2 & 2.8 & 0.58 & 0.62 & 0.13 & 501 & 405 \\
\hline LIN & 4685289 & 309108 & 9 & 9 & 4.1 & 2.8 & 0.57 & 0.52 & 0.15 & -281 & 142 \\
\hline SE & 4697150 & 308647 & 8 & 8 & 4.3 & 3.0 & 0.68 & 0.66 & -0.01 & 111 & -217 \\
\hline MAN & 4699206 & 317237 & 16 & 16 & 4.0 & 2.0 & 0.49 & 0.45 & -0.07 & -144 & -29 \\
\hline CAR & 4702335 & 308243 & 6 & 6 & 2.9 & 2.2 & 0.46 & 0.55 & 0.10 & 362 & -154 \\
\hline MAY & 4706991 & 316586 & 14 & 14 & 5.0 & 3.0 & 0.63 & 0.65 & 0.01 & 161 & -35 \\
\hline DIE & 4710657 & 313622 & 8 & 8 & 3.8 & 2.2 & 0.47 & 0.52 & 0.14 & 162 & -274 \\
\hline CAN & 4711368 & 315523 & 20 & 20 & 4.6 & 2.3 & 0.65 & 0.53 & -0.25 & -212 & 24 \\
\hline RAQ & 4712540 & 319786 & 11 & 11 & 5.1 & 2.7 & 0.68 & 0.63 & -0.10 & -202 & 70 \\
\hline SEN & 4713904 & 318812 & 20 & 20 & 5.4 & 3.0 & 0.71 & 0.63 & -0.15 & -197 & -4 \\
\hline ERA & 4716025 & 320422 & 17 & 17 & 5.0 & 2.7 & 0.71 & 0.63 & -0.13 & -262 & 72 \\
\hline Average & & & 13 & 13 & 4.4 & 2.6 & 0.60 & 0.59 & -0.02 & & \\
\hline Standard deviation & & 4 & 4 & 0.2 & 0.1 & 0.03 & 0.02 & 0.05 & & \\
\hline
\end{tabular}

Table 1. Results of genetic diversity measures for natural populations of Myriophyllum alterniflorum, geographic origins (UTM) and values of the first two principal components (PCA1, PCA2) to the environmental features in the study ponds. Number of ramets (population size), number of genets (number of genotypes), mean number of alleles $\left(\mathrm{N}_{\mathrm{a}}\right)$, mean number of effective alleles $\left(\mathrm{N}_{\mathrm{e}}\right)$, observed heterozygosity $\left(\mathrm{H}_{\mathrm{o}}\right)$, unbiased expected heterozygosity $\left(\mathrm{uH}_{\mathrm{E}}\right)$ and inbreeding coefficient $\left(\mathrm{F}_{\mathrm{IS}}\right)$.

\section{Results}

Genetic diversity. A total of 142 genets were revealed in the samples. All of the obtained genotypes were population specific. Thus, no clones were found between or within populations, suggesting that dispersal of vegetative propagules is uncommon in M. alterniflorum. Total genetic diversity $\left(\mathrm{H}_{\mathrm{T}}\right)$ and mean within-population diversity $\left(\mathrm{H}_{\mathrm{S}}\right)$ were 0.65 and 0.56 , respectively. Considering all study populations, the number of genets, the mean number of alleles $\left(\mathrm{N}_{\mathrm{a}}\right)$ and the mean effective number of alleles $\left(\mathrm{N}_{\mathrm{e}}\right)$ ranged from 6.0 to $20,2.9$ to 5.4, and 2.0 to 3.0, with a mean of $13,4.4$ and 2.6, respectively. The mean observed heterozygosity $\left(\mathrm{H}_{\mathrm{o}}\right)$ and the mean unbiased expected heterozygosity $\left(\mathrm{uH}_{\mathrm{E}}\right)$ were 0.60 and 0.56 , varying between $0.47-0.71$ and $0.45-0.66$, respectively (Table 1$)$. The pairwise Nei's unbiased genetic distance $\left(D_{A}\right.$; Supplementary Table $\left.S 1\right)$ ranged from 0.01 to 0.62 , with comparisons involving individuals from AMO-MAN and RAQ-ERA-CAN presenting the greatest and the smallest genetic dissimilarity, respectively (see Fig. 1 for abbreviations). The population-specific $\mathrm{F}_{\text {IS }}$ varied from -0.25 to 0.15 , with an average of -0.02 (Table 1 ). The mean values of $F_{I T}$ and $F_{S T}$ were 0.11 and 0.13 , respectively, suggesting moderate genetic differentiation and limited inbreeding between populations.

Population genetic structure. The STRUCTURE analysis (Fig. 1) suggested $\mathrm{K}=2$ as the optimal number of clusters based on the second order rate of change of the likelihood function, $\Delta K$ (Supplementary Fig. S1). One geographical group consisted of populations from the northern part of the study area (ERA, SEN, RAQ, CAN, DIE, MAY, CAR and MAN), while the other cluster comprised populations from the south (SE, LIN and $A M O)$. Four ponds (MAN, SE, LIN and AMO) showed the greatest genetic divergence $\left(\mathrm{F}_{S T} ;\right.$ Fig. 1). Discriminant Analysis of Principal Components (DAPC) was performed on the first 40 principal components to capture nearly $90 \%$ of the total genetic variation. Results of the DAPC analysis (Supplementary Table S2) were analogous to those from the STRUCTURE. In summary, the individual density plot on the first discriminant function revealed a clear separation between the two population clusters identified by the Bayesian clustering approach (Fig. 2a).

The minimum spanning network (MSN) plotted by EDENetworks (Fig. 2b) revealed several distinct topological features. The network drawn from the distribution of alleles between populations indicated a clear separation between the two clusters identified by the STRUCTURE and DAPC analyses. Similarly, a consistent patterns for barriers to gene flow was observed with the Monmonier's algorithm (Fig. 2b). The single geographic boundary was the one separating the three southern ponds (LIN, AMO and SE) from all populations north of SE. Consequently, MSN and Monmonier's algorithm seemed to confirm our previous results, suggesting that the three southern populations (SE, LIN, AMO) exhibited a strong isolation by distance and experienced very limited gene flow from northern ponds. Conversely, populations from the northern cluster were likely to be relatively well connected by a number of links, with CAN functioning as a connectivity provider for nearby ponds.

Landscape genetic analysis. After the PCA-based model selection procedure, we kept the first two axes as synthetic environmental variables since these two principal components explained $~ 98 \%$ of the variance in the environmental attributes. The first axis was closely associated with turbidity, nutrient content and hydroperiod length, while $\mathrm{pH}$ and conductivity had the largest independent contribution for variation in the second axis (Supplementary Table S3).

Our analyses by Mantel test suggested a significantly positive correlation between genetic and geographic distances $(r=0.82, p=0.001)$, whereas non-significant associations were detected between genetic differentiation and environmental dissimilarity $(r=0.50, p=0.1)$. When the influence of the environmental factor was controlled, the genetic-spatial association remained highly significant $(r=0.78, p=0.001$; Table 2; Fig. 3). According to the MMRR, geographic distance had the highest regression coefficient $(\beta=0.71, p=0.005)$, while the effects of environmental heterogeneity were again statistically non-significant $(\beta=0.13, \mathrm{p}=0.86)$. 


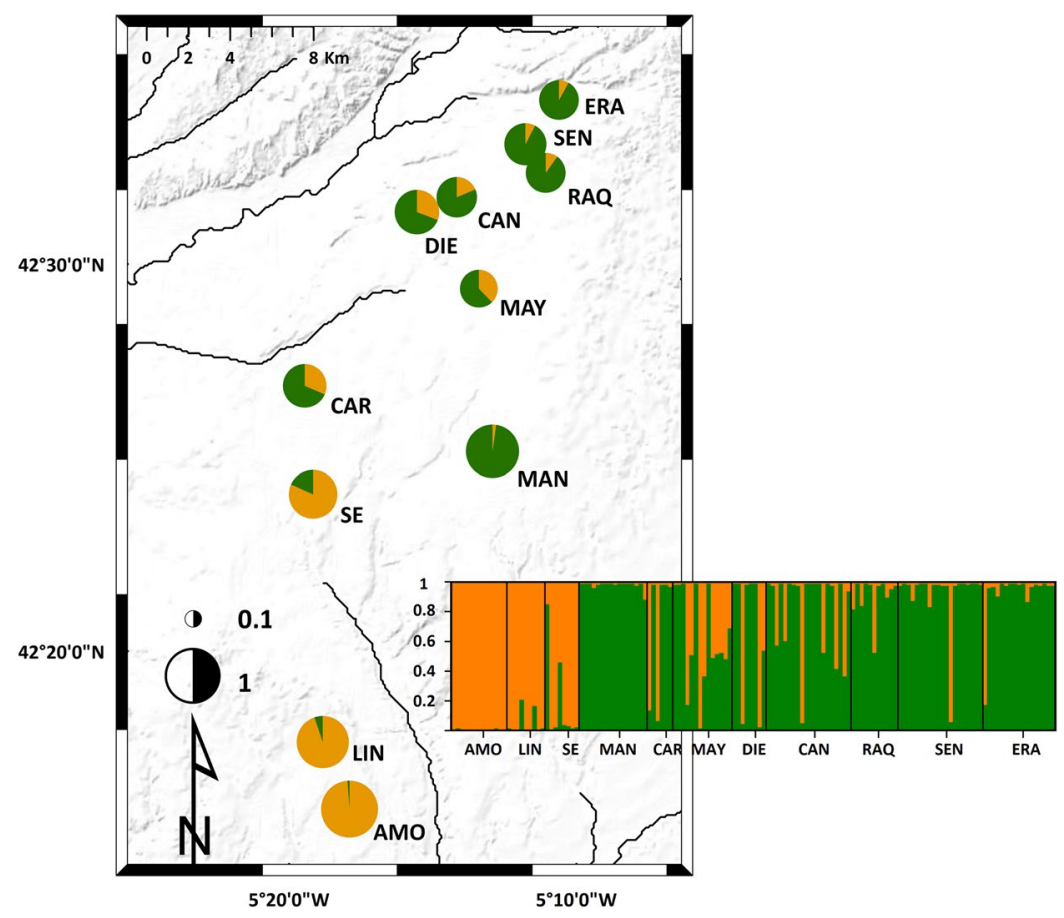

Figure 1. Estimated genetic structure of Myriophyllum alterniflorum populations inferred by a Markov chain Monte Carlo clustering (STRUCTURE) at the individual level $(K=2)$. Black lines indicate different population origins. Pie charts represent the probability of assignment to one of the two clusters (orange: southern cluster; green: northern cluster). The areas of the pie charts are proportional to the mean $\mathrm{F}_{\mathrm{ST}}$ values over loci. The colour scales are used in Fig. 2.

a

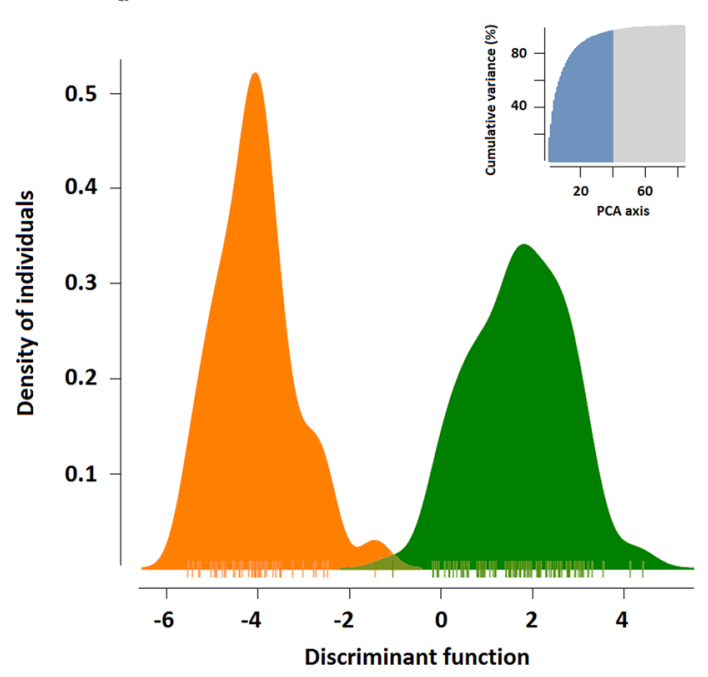

b

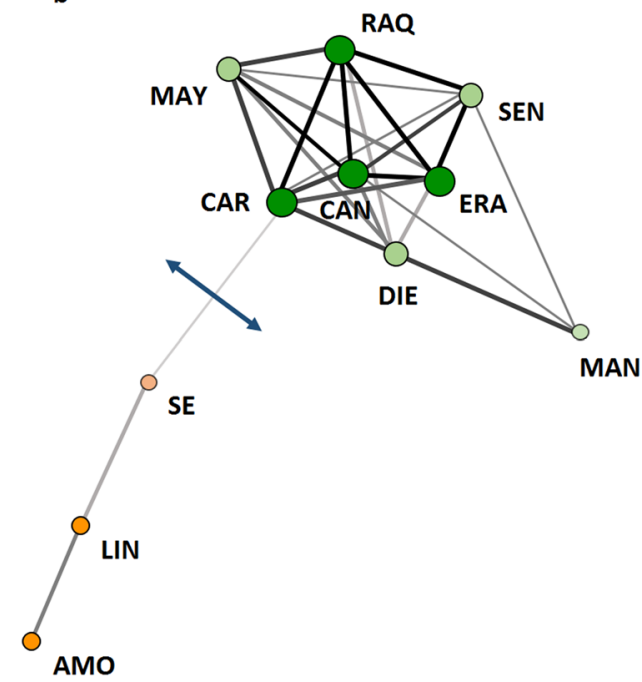

Figure 2. (a) Discriminant analysis of principal components (DAPC) showing the individual density plot on the first discriminant function $(k=2)$. The top right histogram illustrates the amount of variation explained by the principal components (PCAs $=40$ ). (b) Simplified network identified by EDENetworks between nodes (sampling sites). Line thickness is proportional to linkage strength and node size is proportional to the number of linkages for each population. The blue line indicates the position of the single barrier to gene flow for more than half the loci set identified by the Monmonier's algorithm after 1,000 bootstrap replicates.

\section{Discussion}

Compared with previous works on patterns of genetic differentiation in aquatic macrophytes ${ }^{23-26}$, the present study was performed along a relatively wide environmental gradient in a Mediterranean landscape. Estimates of genetic diversity (i.e. total diversity, $\mathrm{H}_{\mathrm{T}}$; mean within-population diversity, $\mathrm{H}_{\mathrm{S}}$; observed heterozygosity, $\mathrm{H}_{\mathrm{o}}$; 


\begin{tabular}{|l|l|l|l|}
\hline Landscape feature & Controlled & r & $\boldsymbol{p}$ \\
\hline Geographic distance & & $\mathbf{0 . 8 2}$ & $\mathbf{0 . 0 0 1}$ \\
\cline { 3 - 4 } Environmental dissimilarity & & 0.50 & 0.06 \\
\hline Geographic distance & Environmental dissimilarity & $\mathbf{0 . 7 8}$ & $\mathbf{0 . 0 0 1}$ \\
\hline Environmental dissimilarity & Geographic distance & 0.31 & 0.11 \\
\hline
\end{tabular}

Table 2. Simple and partial Mantel tests showing correlations between genetic distance, geographic distance and environmental dissimilarity. Significant values are presented in bold.

a

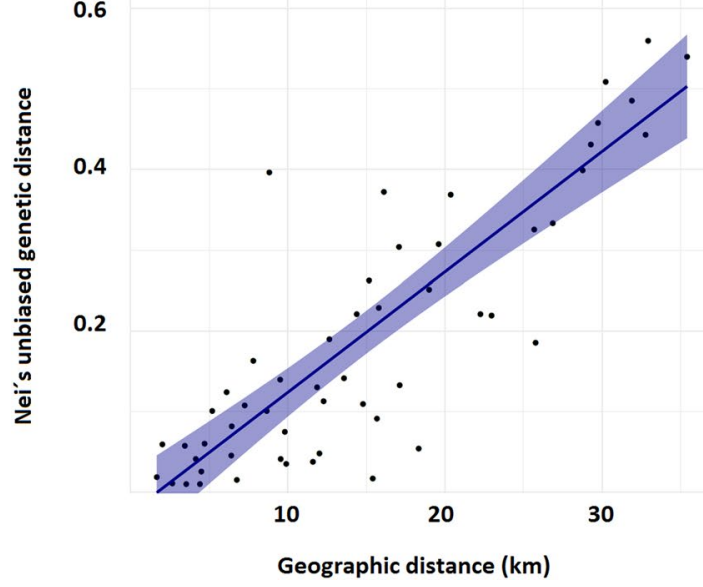

b

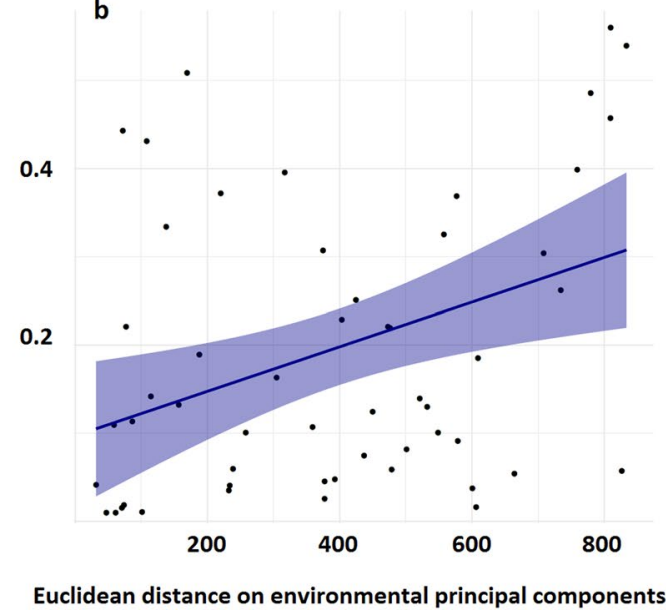

Figure 3. Scatter plots of Mantel tests showing the relationships between genetic differentiation, geographic distance (a) and environmental dissimilarity (b).

and unbiased expected heterozygosity, $\mathrm{uH}_{\mathrm{E}}$ ) for M. alterniflorum populations were somewhat high compared to the average values reported for other aquatic macrophytes with similar life history traits at both the species and the population level ${ }^{17,18,27}$. The possible reason for the relatively high genetic variation uncovered here may be explained in terms of high landscape heterogeneity and the wide range of local ecological conditions of the study pond $s^{28}$. Likewise, all the obtained genotypes were population-specific, suggesting a high rate of recombination due to sexual reproduction and uncommon interpopulation dispersal of vegetative propagules ${ }^{29}$. In this regard, García-Girón et al. ${ }^{30}$ recently showed that seeds of $M$. alterniflorum were far more frequently encountered in surface sediment than its vegetative plant fragments, supporting our assumption that the spread of vegetative propagules is a relatively rare event. In any case, these patterns of genetic variability suggest that Mediterranean ponds are important reservoirs of genetic diversity ${ }^{25}$.

In spite of the relatively short distances between ponds (mean pairwise geographic distance $\sim 15 \mathrm{~km}$ ), and following our expectations (H2), populations clustered into genetic groups that mirrored their geographic patterns. Indeed, the Bayesian clustering approach and the discriminant analysis of principal components found only two genetic clusters in the data, one comprised of the eight populations north of SE and the other comprised of SE and the two populations south of this pond. This grouping was supported by the EDENetwork analysis, which also found modest levels of population connectivity. Sites spanning the northern cluster were relatively well connected, with the centrally located CAN being an important node linking several sites (Fig. 2b). This finding highlights the degree to which stepping-stone ponds may function as habitat connectivity providers for short-distance seed exchanges among otherwise isolated habitat patches ${ }^{4}$. By contrast, sites south of SE showed less population connectivity and seemingly were not linked to the northernmost populations, suggesting that gene flow was not sufficient to keep a single, panmictic, spatially extended population throughout the study range. This finding is intuitive given that ponds spanning the southern cluster were largely isolated from the northernmost sites (see Fig. 1), so the further apart ponds were, the less likely they were to share a similar allelic composition. This is especially true when little or no physical connection via flowing water exists between the sites ${ }^{20}$ (see below). Accordingly, the Monmonier's algorithm indicated that there was a single barrier to gene flow, isolating the southernmost populations front the rest of the species' range. This means that geographic limits will decrease the probability of effective dispersal among distant populations and thus enhance differentiation through genetic drift ${ }^{31}$.

It is generally accepted that IBD and IBE are the main scenarios structuring genetic divergence in natural populations ${ }^{4}$. However, only a few empirical studies have assessed the relative role of geographic distances and environmental factors in shaping genetic patterns of aquatic macrophyte populations ${ }^{32}$, and most of them come from temperate Europe ${ }^{33,34}$ and Asia ${ }^{16-18}$. To the best of our knowledge, no academic work has yet examined the actual patterns of gene flow in aquatic macrophytes from Mediterranean landscapes and whether there is a prevailing scenario with respect to spatial and environmental gradients. This particular situation has led Mediterranean ecologists to understand organism-landscape interactions in terms of the well-established theory 
of metacommunity organization, in which the interplay of spatial processes and local environmental forces is determined by performing robust, mechanistic models ${ }^{20,21}$. However, such an indirect approach produces information on the influence of spatial processes, environmental filtering, and both in combination, from coarse proxies of dispersal, such as eigenfunction spatial analyses ${ }^{7}$ and distance decay functions ${ }^{35}$, potentially overfitting the environmental component ${ }^{8}$. Hence, incorporating more realism in the genetic architecture of dispersal may play an important role in advancing our understanding on how landscape variation shapes the distribution of aquatic macrophytes in this kind of highly fragmented environments. Since extensive Mediterranean environments are found in several locations worldwide and are relatively sensitive to climate and land-use change ${ }^{36}$, addressing this knowledge gap has important, widespread implications.

In our study, a strong association between genetic and geographic distances revealed a pattern of IBD across the distributional range of M. alterniflorum in northern Spain, partially confirming our main hypothesis (H1). Under this scenario, increasing geographic distances among populations is expected to lead to enhanced genetic differentiation ${ }^{4-15}$, which essentially requires that gene flow occurs primarily between neighbouring populations $^{31}$. Several previous studies revealed strong interpopulation genetic divergence and patterns of IBD in aquatic macrophytes at the continental scale ${ }^{16-18}$. However, to our knowledge, our study is the first empirical evidence that links macrophyte genetic variation and geographic isolation at the regional scale in Mediterranean landscapes. Globally, our study suggests that the dispersal of M. alterniflorum individuals among Mediterranean ponds was limited by geographic isolation and argues in favour of the classical stepping-stone model in which gene flow is mostly restricted to neighbour populations ${ }^{31}$.

Wind, water and animals are the three main agents of dispersion for aquatic macrophytes, but their relative roles are very different. For example, Sommers et al..$^{5}$ found that hydrochory is a common means of long-distance dispersal in wetland species, facilitating gene exchange among geographically isolated populations and reducing the effect of founder events and genetic drift ${ }^{37}$. In fact, water dispersal has long been recognized as the main reason for the wide distribution of freshwater macrophytes ${ }^{38}$. Given the few hydrological connections among the study ponds $s^{39}$, wind and animals were likely to play the primary role for inter-population gene flow, transporting pollen, seeds and vegetative propagules to other ponds over the landscape ${ }^{20}$. Since wind-mediated gene flow seems to be effective only for distances of less than $1 \mathrm{~km}^{40}$, anemochorous dispersal may have failed to homogenize allele frequencies across distant populations. This reasoning is also in agreement with other experimental studies that have investigated spatial genetic structure of submerged macrophyte species in wetlands ${ }^{34}$. On the other hand, some waterbirds are known to play an important role in the seed dispersal of watermilfoils ${ }^{41}$. However, given the small populations of indigenous and migratory waterfowl in the study area ${ }^{39}$, we speculate that bird-mediated dispersal was likely to be of minor importance for gene flow patterns. Therefore, the single means of dispersal and lack of mediators (i.e. water and birds) may have enhanced genetic differentiation of $M$. alterniflorum populations in Mediterranean ponds, which could explain the greater prediction of IBD on genetic divergence as a result of genetic drift and dispersal limitation ${ }^{16}$.

Since the traditional view of macrophyte community studies is founded on the principle of environmental determinism ${ }^{9,42}$, the results we report here may seem surprising. However, recent empirical research ${ }^{8,20}$ suggests $^{2}$ that spatial structuring and environmental control together accounts for much of the variation in aquatic macrophyte communities at different spatial scales and geographic areas. For example, using a novel combination of metacommunity assembly modelling and multivariate multiscale codependence analysis, García-Girón et $a l .{ }^{20}$ showed that dispersal limitation acted in concert with species sorting to influence macrophyte community assembly processes in Mediterranean landscapes. In this regard, a growing number of studies ${ }^{20,21,43}$ recognize that metacommunity theory must go beyond the historically predominant thinking of considering environmental determinism as the main scenario of macrophyte community assembly. For example, Brown et al. ${ }^{2}$ emphasized the degree to which dispersal limitation interferes with environmental filtering by hindering species' tracking of local environmental conditions. By using effective (genetic) dispersal estimates, our results are broadly in line with recent findings from metacommunity theory ${ }^{20,21}$ (confirming our third hypothesis, H3) and re-emphasize the need to go beyond the historically predominant paradigm of understanding environmental heterogeneity as the main force driving macrophyte gene flow patterns.

Studies of single species are undoubtedly valuable for population genetics, often providing greater power and resolution for examining patterns of biological variation than coarse proxies of dispersal from spatial eigenfunction analyses ${ }^{14}$. However, since most metacommunities comprise dozens to hundreds of species, adding additional species to the analysis would provide a big step further for examining how ecological and landscape variation shapes the distribution of genetic diversity in nature ${ }^{10,14}$. For the moment, our study is an important step towards integrating population genetics into the full inference space of metacommunity ecology. Different types of approaches for molecular-based studies, including large multi-species population genetic data and DNA barcoding of entire assemblages ${ }^{10}$, will play a major part in the next big steps, providing an exciting frontier for metacommunity ecology that may open up many advances of scientific inquiry.

In conclusion, we highlighted the influence of spatial processes on patterns of genetic differentiation in $M$. alterniflorum under a relatively wide environmental gradient in Mediterranean ponds. Despite the relatively short distances between the study ponds (mean pairwise geographic distance $\sim 15 \mathrm{~km}$ ), plant populations clustered into genetic groups that mirrored their geographic distributions. Perhaps more importantly, we found a significant correlation between genetic variation and geographic distance at the regional scale, which essentially requires that gene flow occurs primarily between nearby populations. Accordingly, these findings emphasise that dispersal limitation at the landscape level may be an additional point of major conservation concern for aquatic macrophytes. Further studies examining the processes structuring genetic variation of multiple aquatic macrophyte species are needed to demonstrate whether the pattern provided by M. alterniflorum is typical or anomalous for macrophytes in this kind of highly fragmented landscapes. Hence, comparative studies, either of population genetics, 
metacommunity ecology or both in combination, will help us obtain a deeper understanding of whether or not spatial processes may hinder aquatic macrophyte species from tracking environmental variation.

\section{Methods}

Site description. We performed this study on 11 ponds located in a central, lowland area (around $900 \mathrm{~m}$ above the sea level) of approximately $200 \mathrm{~km}^{2}$ in northern Spain (Supplementary Fig. S2). The predominant land uses in the study area are arable and pasture and the climate is Mediterranean dry moderate. The majority of ponds studied are fed mostly by groundwater and rainfall and experience a strong reduction in water volume during the summer, ranging between 0.7 and 4.8 ha in aerial extent and 0.3 and $1.5 \mathrm{~m}$ in depth. The site selection included ponds with considerable variability in environmental conditions, including morphometry, nutrient content and mineralization (Supplementary Table S4).

Species biology. Alternateflower watermilfoil (M. alterniflorum) is an anchored submerged aquatic macrophyte that is native to Europe, North America and Asia ${ }^{44}$. This widespread aquatic species occurs in still or slow-moving, neutral to basic water $(\mathrm{pH}=6.0-8.8)$ of lakes, ponds and rivers with typically nutrient-poor and fine mineral sands sometimes mixed with $\operatorname{muck}^{44,45}$. M. alterniflorum presents diverse reproduction modes dispersing through both sexual and vegetative propagules (rhizomes and plant fragments). Similarly, this macrophyte species is typically dispersed by wind, water and waterfow ${ }^{45}$. Together, gamete vectors and reproductive traits of this aquatic macrophyte species are expected to result in high gene flow and dispersal rates among nearby populations $\mathrm{s}^{22}$.

Environmental data. Pond area (ha) was measured on high resolution aerial images with ArcMap version 10.6 (Esri, Redlands, CA, USA). Maximum depth (m) and Secchi depth (m) were recorded in the deepest area of each waterbody using calibrated sticks and a Secchi discs (diameter $=20 \mathrm{~cm}$ ), respectively. The ratio Secchi depth:maximum pond depth was used as a variable instead of Secchi depth since most of the ponds were shallow enough to keep the disc visible up to the bottom. Hydroperiod length (i.e. water residence time) was coded as a set of dummy variables, one for each category of the variable (permanent, temporary). Several water samples were randomly collected at different depths along a shore-centre transect using a cylindrical corer (diameter $=60 \mathrm{~mm}$, length $=1 \mathrm{~m}$ ). All samples from each pond were subsequently mixed to form a single composite water sample (volume $=51$ ). Conductivity and $\mathrm{pH}$ were measured in the field from the composite water sample using WTW probes (Xylem, Weilheim, Germany). The integrated water samples were preserved in Pyrex glass bottles at $4^{\circ} \mathrm{C}$ and then analysed in laboratory following standard methods $s^{46}$ to determine total suspended solids, nitrate, ammonium, total phosphorous, soluble reactive phosphorus, chlorophyll " $a$ ", chlorides and sulphates.

Plant sampling. A total of 142 individuals of $M$. alterniflorum were collected from 11 ponds in July 2018 . Six to 20 young leaf fragments from each population were randomly sampled at 2-3 m intervals to avoid collecting ramets from a single genet. Fresh leaf samples were immediately dried in allochroic silica gel in the field and then stored frozen at $-80^{\circ} \mathrm{C}$ before being processed further.

DNA extraction and PCR amplification. Total genomic DNA was extracted from fresh leaf samples using the DNeasy ${ }^{\circledR}$ Plant Mini Kit (QIAGEN, Hilden, Germany) and following the manufacturer' protocol. From the 20 microsatellite primers designed by Wu et al. ${ }^{47}$, we selected a total of nine loci with clear polymorphic and reproducible bands (Supplementary Table S5). PCR amplifications were carried out in a volume of $25 \mu$ l containing a

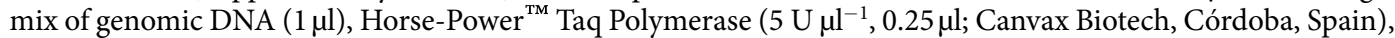
SSR primers $(10 \mu \mathrm{M}, 2 \mu \mathrm{l}$; Thermo Fisher Scientific, Waltham, MA, USA), dNTPs ( $10 \mathrm{mM}$ each, $2.5 \mu \mathrm{l})$, buffer and $\mathrm{Cl}_{2} \mathrm{Mg} 25 \mathrm{mM}(2.5 \mu \mathrm{l} \mathrm{each})$. PCR reactions consisted of an initial denaturation period of $5 \mathrm{~min}$ at $94^{\circ} \mathrm{C}$, followed by 35 cycles of $94^{\circ} \mathrm{C}$ for $30 \mathrm{~s}, 52-59^{\circ} \mathrm{C}$ for $30 \mathrm{~s}$ and $72^{\circ} \mathrm{C}$ for $1 \mathrm{~min}$, and a final $10 \mathrm{~min}$ extension at $72^{\circ} \mathrm{C}$, after which the samples were preserved at $4^{\circ} \mathrm{C}$. Genotyping was performed on an ABI 3130XL (Applied Biosystems, Foster City, CA, USA) automated DNA sequencer using an internal size standard (GeneScan ${ }^{\mathrm{TM}} 500 \mathrm{Liz}^{\circledR}$, Applied Biosystems) for accurate sizing. Then, GeneMapper version 4.0 (Applied Biosystems) was used for allele calling.

Genetic diversity. Genetic diversity estimates, such as allele richness $\left(\mathrm{N}_{\mathrm{a}}\right.$ and $\left.\mathrm{N}_{\mathrm{e}}\right)$, total genetic diversity $\left(\mathrm{H}_{\mathrm{T}}\right)$, mean genetic diversity $\left(\mathrm{H}_{\mathrm{S}}\right)$, and observed and expected heterozygosities $\left(\mathrm{H}_{\mathrm{o}}\right.$ and $\left.\mathrm{uH}_{\mathrm{E}}\right)$, were computed with GenAlEx version $6.5^{48}$. Nei's unbiased genetic distance ${ }^{49}\left(\mathrm{D}_{\mathrm{A}}\right)$ and Wright's $\mathrm{F}$ statistics ${ }^{50}$, including inbreeding coefficient $\left(\mathrm{F}_{\mathrm{IS}}\right)$, total inbreeding $\left(\mathrm{F}_{\mathrm{IT}}\right)$ and fixation index $\left(\mathrm{F}_{\mathrm{ST}}\right)$, were also determined with the same statistical software. Clone assignment was conducted with the criterion of treating individuals with the same multilocus genotype as a clone, and only the genotypes of the genets were kept for subsequent analyses.

Population genetic structure. The number of genetic clusters of the 11 alternateflower watermilfoil populations was assessed by using a Bayesian clustering method implemented in the software STRUCTURE version $2.3^{51}$. We tested $K$ (i.e., the number of clusters) in ten independent runs from 1 to 11 (burn-in period of 10,000 iterations and 10,000 Markov chain Monte Carlo, MCMC, replicates in each run), without using sampling site as a prior to assess convergence of the estimated In probability of the data, In $P(D)$. Runs were carried out under the admixture model with independent allele frequencies. The best-fit number of clusters was calculated based on the second order rate of change of the likelihood function, $\Delta K^{52}$. Discriminant analysis of principal components ${ }^{53}$ (DAPC) was also carried out as an alternative method for determining broad-scale population structure using the dapc function from the 'adegenet' package version $2.1 .1^{54}$ in R. DAPC is a multivariate approach that combines principal component analysis together with discriminant analysis to summarize genetic differentiation between groups. DAPC is free of assumptions about Hardy-Weinberg equilibrium or linkage disequilibrium and provides graphical representation of the divergence among populations. The method requires a priori clustering 
algorithms determined by $k$-means. We evaluated up to $k=11$ groups, and Bayesian information $\operatorname{criterion}^{53}(B I C)$ was used to assess the number of clusters best fitting the data. However, the value of BIC kept decreasing with the increase of $k$. We therefore set an identical $k$ values as the $K$ of STRUCTURE for comparison ${ }^{16}$.

We created a minimum spanning network (MSN) to illustrate patterns of gene flow between populations using EDENetworks version $2.18^{55}$. The method is a divisive-hierarchical clustering-like process in which the network is scanned from a fully connected state to a critical threshold distance (i.e. percolation threshold) without $a$ priori assumptions of the clustering of populations. The software plots all populations as nodes in a network graph with connections (links or edges) between nodes weighted by their pairwise Nei's unbiased genetic distance $\left(D_{A}\right)$. The layout of the MSN was recomputed 10 times to test for possible alternative network shapes.

We applied the Monmonier's maximum difference algorithm ${ }^{56}$ as implemented in the package 'adegenet' to identify the geographic areas associated with genetic discontinuities in the study populations. The initial connection network was built using UTM coordinates for the sites. Detection of genetic discontinuities was based on the Delauney triangulation and the resulting Voronoi tessellation. Each edge of the Voronoi polygons was associated with the value of the corresponding $\mathrm{D}_{\mathrm{A}}$ between pairs of populations. The algorithm then built genetic boundaries based on maximum pairwise distances ${ }^{56}$. Statistical confidence of the genetic barriers detected, corresponding to an abrupt change in the patterns of genetic variation among populations, was evaluated using 1,000 bootstrap replicates that were simulated with the function writeBoot from the package 'diveRsity' version $1.9^{57}$. Analyses were also conducted separately for each amplifying microsatellite locus.

Landscape genetic analysis. We reduced the available environmental variables to a more parsimonious set by performing principal component analysis (PCA) on independent environmental attributes (Spearman's rank correlation $r_{s}<0.7$ ) with the princomp function from the 'vegan' package version $2.4^{58}$. After dealing with multicollinearity, local environmental attributes included: hydroperiod length, aerial extent, depth, relative Secchi depth, $\mathrm{pH}$, conductivity, total suspended solids, ammonium, total phosphorous and chlorophyll " $a$ ". The environmental (Euclidean) distances between populations were calculated from the values obtained from the PCA-based model selection procedure. Both geographic (Euclidean distances between pond UTM coordinates) and environmental distance matrices were constructed using the vegdist function from the 'vegan' package. The correlations between geographic/environmental factors and Nei's unbiased genetic distances were assessed by a combination of partial Mantel tests ${ }^{59}$ and multiple matrix regression with randomization ${ }^{60}$ (MMRR). Partial Mantel tests with 10,000 permutations were performed between genetic distances and one factor under the influence of the other (as covariate) using the mantel.partial function implemented in the 'vegan' package. Similarly, MMRR was implemented with 10,000 iterations to estimate the independent effect of geographic/environmental factors using the MMRR function script ${ }^{60}$. The main advantages of this method are that it produces appropriate levels of Type-I error $^{60}$, and it uses multiple regression, assessing the independent contribution of each variable in the model.

\section{Data availability}

The data sets generated during and/or analysed during the current study are available from the corresponding author on reasonable request.

Received: 11 June 2019; Accepted: 19 November 2019;

Published online: 02 December 2019

\section{References}

1. Jordano, P. What is long-distance dispersal? And a taxonomy of dispersal events. J. Ecol. 105, 75-84 (2017).

2. Brown, B. L., Solos, E. R., Skelton, J. \& Tornwall, B. Making sense of metacommunities: dispelling the mythology of a community typology. Oecologia 183, 643-652 (2017).

3. Leibold, M. A. et al. The metacommunity concept: a framework for multi-scale community ecology. Ecol. Lett. 7, 601-613 (2004).

4. Sexton, J. P., Hangartner, S. B. \& Hoffmann, A. A. Genetic isolation by environment or distance: which pattern of gene flow is most common? Evolution 68, 1-15 (2014).

5. Soomers, H. et al. Wind and water dispersal of wetland plants across fragmented landscapes. Ecosystems 16, 434-451 (2013).

6. Chust, G. et al. Dispersal similarly shapes both population genetics and community patterns in the marine realm. Sci. Rep. 6, 28730, https://doi.org/10.1038/srep28730 (2016).

7. Borcard, D. \& Legendre, P. All-scale spatial analysis of ecological data by means of principal coordinates of neighbor matrices. Ecol. Model. 153, 51-68 (2002).

8. Clappe, S., Dray, S. \& Peres-Neto, P. R. Beyond neutrality: disentangling the effects of species sorting and spurious correlations in community analysis. Ecology 99, 1737-1747 (2018).

9. Alahuhta, J. et al. Global patterns in the metacommunity structuring of lake macrophytes: regional variations and driving factors. Oecologia 188, 1167-1182 (2018).

10. Heino, J. et al. Metacommunity organisation, spatial extent and dispersal in aquatic systems: patterns, processes and prospects. Freshwater Biol. 60, 845-869 (2015).

11. Hindley, J. A., Graham, B. A., Pulgarin, P. C. \& Burg, T. M. The influence of latitude, geographic distance, and habitat discontinuities on genetic variation in a high latitude montane species. Sci. Rep. 8, 11846, https://doi.org/10.1038/s41598-018-29982-7 (2018).

12. Hildrew, A. G. Sustained research on stream communities: a model system and the comparative approach. Adv. Ecol. Res. 41, 175-312 (2009).

13. Finn, D. S., Bonada, N., Murria, C. \& Hughes, J. M. Small but mighty: headwaters are vital to stream network biodiversity at two levels of organization. J. N. Am. Benthol. Soc. 30, 963-980 (2011).

14. Wang, I. J. \& Bradburd, G. S. Isolation by environment. Mol. Ecol. 23, 5649-5662 (2014)

15. Slatkin, M. Gene flow and the geographic structure of natural populations. Science 236, 787-792 (1987).

16. Wu, Z., Yu, D., Wang, Z., Li, X. \& Xu, X. Great influence of geographic isolation on the genetic differentiation of Myriophyllum spicatum under a steep environmental gradient. Sci. Rep. 5, 15618, https://doi.org/10.1038/srep15618 (2015).

17. Wu, Z., Yu, D., Li, X. \& Xu, X. Influence of geography and environment on patterns of genetic differentiation in a widespread submerged macrophyte, Eurasian watermilfoil (Myriophyllum spicatum L., Haloragaceae). Ecol. Evol. 6, 460-468 (2016).

18. Cao, Q. J., Mei, F. F. \& Wang, L. Population genetic structure in six sympatric and widespread aquatic plants inhabiting diverse lake environments in China. Ecol. Evol. 7, 5713-5723 (2017). 
19. Harris, S. A., Maberly, S. C. \& Abbott, R. J. Genetic variation within and between populations of Myriophyllum alterniflorum DC. Aquat. Bot. 44, 1-21 (1992).

20. García-Girón, J., Wilkes, M., Fernández-Aláez, M. \& Fernández-Aláez, C. Processes structuring macrophyte metacommunities in Mediterranean ponds: combining novel methods to disentangle the role of dispersal limitation, species sorting and spatial scales. J. Biogeogr. 46, 646-656 (2019).

21. García-Girón, J., Fernández-Aláez, C., Fernández-Aláez, M. \& Alahuhta, J. Untangling the assembly of macrophyte metacommunities by means of taxonomic, functional and phylogenetic beta diversity patterns. Sci. Total Environ. 693, 133616, https://doi.org/10.1016/j.scitotenv.2019.133616 (2019).

22. Santamaria, L. Why are most aquatic plants widely distributed? Dispersal, clonal growth and small-scale heterogeneity in a stressful environment. Acta. Oecol. 23, 137-154 (2002).

23. Pollux, B. J. A., Luteijn, A., van Groenendael, J. M. \& Ouborg, N. J. Gene flow and genetic structure of the aquatic macrophyte Sparganium emersum in a linear unidirectional river. Freshwater Biol. 54, 64-76 (2009).

24. Chen, L., Xu, L. \& Huang, H. Genetic diversity and population structure in Vallisneria spinulosa (Hydrocharitaceae). Aquat. Bot. 86, 46-52 (2007)

25. Lambertini, C., Gustafsson, M. H. G., Frydenberg, J., Speranza, M. \& Brix, H. Genetic diversity patterns in Phragmites australis at the population, regional and continental scales. Aquat. Bot. 88, 160-170 (2008).

26. Chen, Y., Li, X., Yin, L., Cheng, Y. \& Li, W. Genetic diversity and migration patterns of the aquatic macrophyte Potamogeton malaianus in a potamo-lacustrine system. Freshwater Biol. 54, 1178-1188 (2009).

27. Wang, B., Song, Z., Liu, G., Lu, F. \& Li, W. Comparison of the extent of genetic variation of Vallisneria natans and its sympatric congener V. spinulosa in lakes of the middle-lower reaches of the Yangtze River. Aquatic. Bot. 92, 233-238 (2010).

28. Van den Broeck, M., Waterkeyn, A., Rhazi, L., Grillas, P. \& Brendonck, L. Assessing the ecological integrity of endorheic wetlands, with focus on Mediterranean temporary ponds. Ecol. Indic. 54, 1-11 (2015).

29. Kitamoto, N. et al. Spatial genetic structure among and within populations of Primula sieboldii growing beside separate streams. Mol. Ecol. 14, 149-157 (2005).

30. García-Girón, J., Fernández-Aláez, C., Nistal-García, A. \& Fernández-Aláez, M. Plant macrofossil assemblages from Surface sediment represent contemporary species and growth forms of aquatic vegetation in a shallow Mediterranean lake. J. Paleolimnol. 60, 495-509 (2018).

31. Sharma, R. et al. Genetic analyses favour an ancient and natural origin of elephants on Borneo. Sci. Rep. 8, 880, https://doi. org $/ 10.1038 / \mathrm{s} 41598-017-17042-5(2018)$

32. Barret, S. C. H., Eckert, C. G. \& Husband, B. Evolutionary processes in aquatic plant populations. Aquat. Bot. 44, 105-145 (1993).

33. Storfer, A., Murphy, M. A., Spear, S. F., Holderegger, R. \& Waits, L. P. Molecular biogeography: where are we now? Mol. Ecol. 19, 3496-3514 (2010).

34. Triest, L., Thi, V. T., Thi, D. L., Sierens, T. \& Geert, A. V. Genetic differentiation of submerged plant populations and taxa between habitats. Hydrobiologia 656, 15-27 (2010).

35. Brown, L. E. et al. Functional diversity and community assembly of river invertebrates show globally consistent responses to decreasing glacier cover. Nat. Ecol. Evol. 2, 325-333 (2018).

36. Peña-Ortiz, C., Barriopedro, D. \& García-Herrera, R. Multidecadal variability of the summer lenght in Europe. J. Climate 28, 5375-5388 (2015).

37. Kudoh, H. \& Whigham, D. F. Microgeographic genetic structure and genetic stricture in Hibiscus moscheutos (Malvaceae) populations. Am. J. Bot. 84, 1285-1293 (1997).

38. $\mathrm{Li}, \mathrm{W}$. Environmental opportunities and constraints in the reproduction and dispersal of aquatic plants. Aquat. Bot. 118, 62-70 (2014).

39. Junta de Castilla y León. Decreto 125/2001, de 19 de abril, por el que se modifica el Decreto 194/1994, de 25 de agosto, y se aprueba la ampliación del Catálogo de Zonas Húmedas de Interés Especial. Preprint at https://bocyl.vlex.es/vid/ampliacion-catalogo-zonashumedas-interes-28710600 (2002).

40. Otero-Arnaiz, A., Casas, A. \& Hamrick, J. L. Direct and indirect estimates of gene flow among wild and managed populations of Polaskia chichipe, an endemic columnar cactus in Central Mexico. Mol. Ecol. 14, 4313-4322 (2005).

41. Brochet, A. L., Guillemain, M., Fritz, H., Gauthier-Clerc, M. \& Green, A. J. Plant dispersal by teal (Anas crecca) in the Camargue: duck guts are more important than their feet. Freshwater Biol. 55, 1262-1273 (2010).

42. Alahuhta, J. \& Heino, J. Spatial extent, regional specificity and metacommunity structuring in lake macrophytes. J. Biogeogr. 40, $1572-1582$ (2013).

43. Meynard, C. N. et al. Disentangling the drivers of metacommunity structure across spatial scales. J. Biogeogr. 40, 1560-1571 (2013).

44. Cirujano, S., Meco, A., García-Murillo, P. \& Chirino, M. Haloragaceae in Flora acuática española. Hidrófitos vasculares. (ed. Real Jardín Botánico) 113-121 (Real Jardín Botánico, 2014).

45. Willby, N. J., Abernethy, V. J. \& Demars, B. O. L. Attribute-based classification of European hydrophytes and its relationships to habitat utilization. Freshwater Biol. 43, 43-74 (2000).

46. Rice, E. W., Baird, R. B., Eaton, A. D. \& Clesceri, L. S. In Standard Methods for the Examination of Water and Wastewater (American Public Health Association, American Water Works Association and Water Environment Federation, 2012).

47. Wu, Z. G., Yu, D. \& Xu, X. W. Development of microsatellite markers in the hexaploid aquatic macrophyte, Myriophyllum spicatum (Haloragaceae). Appl. Plant. Sci. 1, 1200230, https://doi.org/10.3737/apps.1200230 (2013).

48. Peakall, R. \& Smouse, P. E. GenAlEx 6.5: genetic analyses in Excel. Population genetic software for teaching and research - an update. Bioinformatics 28, 2537-2539 (2012).

49. Nei, M. Estimation of average heterozygosity and genetic distance from a small number of individuals. Genetics 89, 583-590 (1978).

50. Wright, S. Isolation by Distance. Genetics 28, 114-138 (1943).

51. Pritchard, J. K., Stephens, M. \& Donnelly, P. Inference of population structure using multilocus genotype data. Genetics 155, 945-959 (2000).

52. Evanno, G., Regnaut, S. \& Goudet, J. Detecting the number of clusters of individuals using the software STRUCTURE: a simulation study. Mol. Ecol. 14, 26-2620 (2005).

53. Jombart, T., Devillard, S. \& Balloux, F. Discriminant analysis of principal components: a new method for the analysis of genetically structured populations. BMC Genetics 11, 94 (2010).

54. Jombart, T. adegenet: a R package for the multivariate analysis of genetic markers. Bioinformatics 24, 1403-1405 (2008).

55. Kivelä, M., Arnaud-Haond, S. \& Saramäki, J. EDENetworks: A user-friendly software to build and analyse networks in biogeography, ecology and population genetics. Mol. Ecol. Resour. 15, 117-122 (2015).

56. Monmonier, M. S. Maximum-difference barriers: An alternative numerical regionalization method. Geogr. Anal. 5, 245-261 (1973).

57. Keenan, K., McGinnity, P., Cross, T. F., Crozier, W. W. \& Prodöhl, P. A. DiveRsity: An R package for the estimation and exploration of population genetics parameters and their associated errors. Methods Ecol. Evol. 4, 782-788 (2013).

58. Oksanen, J. et al. Package 'vegan'. 292 (2017).

59. Smouse, P. E., Long, J. C. \& Sokal, R. R. Multiple regression and correlation extensions of the Mantel tests of matrix correspondence. Syst. Zool. 35, 627-632 (1986)

60. Wang, I. J. Examining the full effects of landscape heterogeneity on spatial genetic variation: a multiple matrix regression approach for quantifying geographic and ecological isolation. Evolution 67, 3403-3411 (2013). 


\section{Acknowledgements}

We thank all the members of the limnology group at the University of Leon for their assistance in field work. This research was funded by the Spanish Ministry of Science and Technology (project CL2017-84176R) and by the Junta of Castilla y León (project LE004G18).

\section{Author contributions}

J.G.G., P.G., M.F.A., E.B.M. and C.F.A. designed the research and conducted the field work. J.G.G. and P.G. carried out the laboratory experiments. J.G.G. analysed the data and drafted the manuscript. All authors contributed to editing and improving the manuscript.

\section{Competing interests}

The authors declare no competing interests.

\section{Additional information \\ Supplementary information is available for this paper at https://doi.org/10.1038/s41598-019-54725-7.}

Correspondence and requests for materials should be addressed to J.G.-G.

Reprints and permissions information is available at www.nature.com/reprints.

Publisher's note Springer Nature remains neutral with regard to jurisdictional claims in published maps and institutional affiliations.

(c) (i) Open Access This article is licensed under a Creative Commons Attribution 4.0 International License, which permits use, sharing, adaptation, distribution and reproduction in any medium or format, as long as you give appropriate credit to the original author(s) and the source, provide a link to the Creative Commons license, and indicate if changes were made. The images or other third party material in this article are included in the article's Creative Commons license, unless indicated otherwise in a credit line to the material. If material is not included in the article's Creative Commons license and your intended use is not permitted by statutory regulation or exceeds the permitted use, you will need to obtain permission directly from the copyright holder. To view a copy of this license, visit http://creativecommons.org/licenses/by/4.0/.

(c) The Author(s) 2019 